\title{
Antineutrophil cytoplasmic antibody-associated vasculitis in presence of positive antiphospholipid antibody: a case report
}

\author{
Maassoumeh Akhlaghi Kalahroodi', Maryam Loghman², Mahsa Ramezanpoor ${ }^{3}$, Reza Shahriarirad ${ }^{4}$ and \\ Ehsan Rahmanian ${ }^{2^{*}}$
}

\begin{abstract}
Background: Antineutrophil cytoplasmic antibody-associated vasculitis is dominated by inflammatory occlusion of small vessels, causing tissue ischemia in various organs. This disorder has rarely been associated with vasculopathy, such as antiphospholipid syndrome.

Case presentation: We report a case of a 48-year-old Persian male presenting with distal digital gangrene along with inflammatory arthralgia. High titers of anti-proteinase 3 and antiphospholipid antibodies (anticardiolipin antibody) were detected in laboratory evaluation. Therefore, a diagnosis of antineutrophil cytoplasmic antibody-associated vasculitis and antiphospholipid syndrome was made and treated with anticoagulant along with monthly pulses of cyclophosphamide and a daily dose of $1 \mathrm{mg} / \mathrm{kg}$ prednisolone.

Conclusion: Our case, along with other reports, illustrates that these two entities can coexist. Therefore, monitoring antiphospholipid antibodies in patients with antineutrophil cytoplasmic antibody-associated vasculitis with or without clinical evidence of any thrombosis and ruling out thrombosis in cases that do not respond to proper treatment of vasculitis may be relevant to prevent irreversible or fatal organ damage.
\end{abstract}

Keywords: Vasculitis, Antineutrophil cytoplasmic antibody, Antiphospholipid syndrome, Case report, Vasculopathy, Antiphospholipid antibodies

\section{Introduction}

Antineutrophil cytoplasmic antibody (ANCA)-associated vasculitis is mainly distinguished by inflammatory occlusion of small vessels, inducing tissue ischemia in several vital organs such as the kidney; the ear, nose, and throat region; airways; central nervous system; and, occasionally, the digestive tract [1]. Antiphospholipid syndrome (APS or Hughes' syndrome) is an autoimmune

*Correspondence: drrahmanianehsan@yahoo.com

2 Fellowship of Rheumatology, Shariati Hospital, Tehran University of Medical Sciences, Tehran, Iran

Full list of author information is available at the end of the article systemic disorder characterized by arterial, venous, or small vessel thrombosis [2]. This entity has been reported in other vasculitides such as Wegener's granulomatosis [WG, or granulomatosis with polyangiitis (GPA)] [3], giant cell arteritis [4], Churg-Strauss syndrome [CSS, or eosinophilic granulomatosis with polyarteritis (EGPA)] [5], and polyarteritis nodosa (PAN) [6]. We report a case of ANCA-associated vasculitis along with positive antiphospholipid antibodies (aPL). original author(s) and the source, provide a link to the Creative Commons licence, and indicate if changes were made. The images or other third party material in this article are included in the article's Creative Commons licence, unless indicated otherwise in a credit line to the material. If material is not included in the article's Creative Commons licence and your intended use is not permitted by statutory regulation or exceeds the permitted use, you will need to obtain permission directly from the copyright holder. To view a copy of this licence, visit http://creativecommons.org/licenses/by/4.0/. The Creative Commons Public Domain Dedication waiver (http://creativeco mmons.org/publicdomain/zero/1.0/) applies to the data made available in this article, unless otherwise stated in a credit line to the data. 


\section{Case presentation}

The patient is a 48-year-old Persian male with repeated episodes of redness of eyes in the last nine years, without pain or irritation, which was diagnosed as scleritis by an ophthalmologist, and was administered prednisolone and azathioprine. After 1.5 years, follow-up was discontinued due to resolution of symptoms.

The patient had a 1-year history of pain in small joints of hands and foot, accompanied by morning stiffness (15 min). Joint pain was more prevalent in the wrists, finger interphalangeal (IP), shoulder, and elbow. He also reported positive history of malaise, with no history of photosensitivity, oral aphthae, ulcer, intestinal diseases, hair loss, Raynaud phenomenon, dryness of eyes or mouth, and skin lesions, upper limb claudication, weight loss, smoking, or any addiction. He also did not have hypertension, diabetes, and any history of thrombosis.

A preliminary diagnosis of rheumatoid arthritis was assumed for the patient by the rheumatologist, and the patient was administered a regimen of prednisolone (7.5 mg/day), methotrexate (10 mg/week), and hydroxychloroquine $(200 \mathrm{mg} /$ day $)$, which resulted in a relative improvement of arthralgia symptoms.

After eight months of following the mentioned treatment regimen, the patient arbitrarily discontinued his drugs due to the COVID-19 pandemic. Consequently, he developed pain and paresthesia in his fingertips with cyanosis of the left index finger from 1 week before visiting us at the rheumatology clinic. On evaluation, there was evidence of cyanosis of the left index finder at its radial side, along with mottling signs and coldness at the distal part of the remaining fingers. Splinter hemorrhage was also observed under the fingernails (Fig. 1).

There was no evidence of arthritis, swelling, or tenderness in his wrist, interphalangeal, and metacarpophalangeal joints. Radial and ulnar pulses were present and symmetric in both hands. Heart and lung auscultation were normal with no signs of heart souffle. No evidence of bruit was detected in carotid, subclavian, abdominal, and renal artery examination. Abdominal and genitalia examinations were normal and without tenderness. Central and peripheral nervous system examinations were unremarkable.

Rheumatological laboratory evaluation demonstrated elevated rheumatoid factor levels with high titers, and cytoplasmic antineutrophil cytoplasmic antibodies (C-ANCA or anti-PR3) was ten times the normal value. Kidney and liver function tests were unremarkable, and the SARS-CoV-2 polymerase chain reaction (PCR) test was negative. Urine analysis was also unremarkable with no presence of cellular cast or protein (WBC: $2-3$ and RBC: $0-3)$. Table 1 demonstrates the laboratory data of our patient.

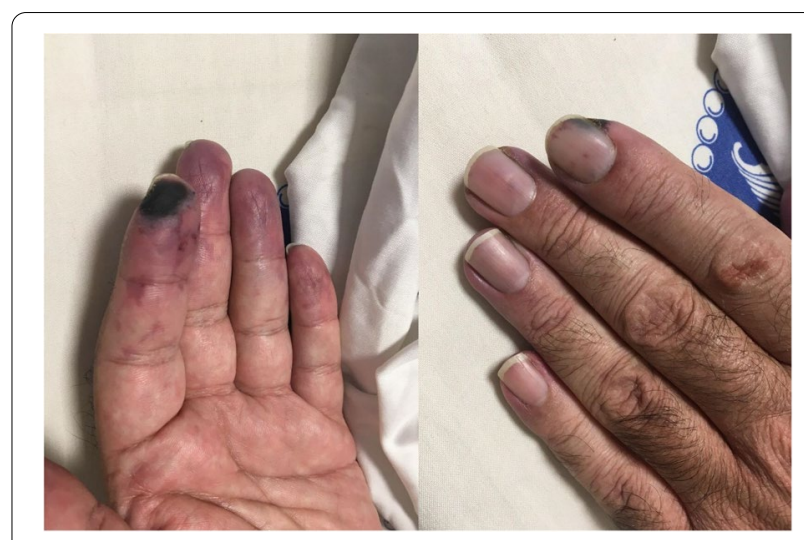

Fig. 1 Gangrene of left index finger along with splinter hemorrhage under fingernails

Electrocardiogram showed normal sinus rhythm. With suspicion of vascular obstruction, color Doppler sonography of the left upper limb artery and vein was performed, being normal with no signs of arterial stenosis or deep venous thrombosis. Cardiac echography was performed and revealed an ejection fraction of 55\% and pulmonary artery pressure of 22, with no evidence of vegetation, mass, or thrombosis. Computed tomography $(\mathrm{CT})$ scan of the lung and paranasal sinuses was normal with no evidence of alveolar hemorrhage, nodules, or cavitation (Fig. 2). Peripheral neurological evaluation through electromyography and nerve conduction velocity (EMG-NCV) test was unremarkable. The patient was also visited by an ophthalmologist, with no signs of uveitis and vasculitis detected, and sclera normal.

Based on a diagnosis of ANCA-associated vasculitis and obstruction of distal arteries of the small terminal artery of the extremities, infusion of methylprednisolone pulse $(1 \mathrm{~g} /$ day) was started for 3 days, followed by venous pulses of cyclophosphamide $(1 \mathrm{~g} /$ monthly $)$ along with oral prednisolone $(1 \mathrm{mg} / \mathrm{kg} /$ day $)$.

During the course of treatment, he was still in pain, and the gangrene process continued. A positive value for aPL was detected, including a two-fold elevation of anticardiolipin (aCL) IgG levels. Therefore, anticoagulants were started for the patient through venous infusion of heparin (5000 unit/stat then $1000 \mathrm{U} / \mathrm{h}$ ) along with oral administration of warfarin $(5 \mathrm{mg} /$ day). Furthermore, ASA ( $80 \mathrm{mg} /$ day), diltiazem $(30 \mathrm{mg}$, thrice a day), and atorvastatin $(40 \mathrm{mg} /$ day) were administered to the patient. Heparin infusion was halted after 3 days, while anticoagulant treatment was continued with warfarin $(5 \mathrm{mg} /$ day). The methylprednisolone 3 day course was followed with oral administration of $1 \mathrm{mg} / \mathrm{kg}$ prednisolone (30 $\mathrm{mg}$, thrice a day). 
Table 1. Laboratory data of 48-year-old patient with index finger cyanosis

\begin{tabular}{|c|c|c|c|}
\hline Test & Reference value & Result & Interpretation \\
\hline White blood cell count $\left(\times 10^{9} / \mathrm{L}\right)$ & $3.5-9.5$ & 9 & Normal \\
\hline Hemoglobin (g/L) & $12-17.5$ & 14.8 & Normal \\
\hline Mean corpuscular volume (fL) & $82-92$ & 87 & Normal \\
\hline Platelet count (mL) & $150-450$ & 329 & Normal \\
\hline Blood urea nitrogen (mg/dL) & $7-20$ & 10 & Normal \\
\hline Creatinine $(\mathrm{mg} / \mathrm{dL})$ & $0.6-1.2$ & 0.9 & Normal \\
\hline Aspartate aminotransferase $(\mathrm{U} / \mathrm{L})$ & $15-40$ & 18 & Normal \\
\hline Alanine aminotransferase $(U / L)$ & $9-50$ & 19 & Normal \\
\hline 24-h urine protein (mg/day) & $<80$ & 126 & Normal \\
\hline Erythrocyte sedimentation rate $(\mathrm{mm} / \mathrm{h})$ & $<22$ & 47 & Elevated \\
\hline C-reactive protein (mg/L) & $0-8$ & $67(3+)$ & Elevated \\
\hline Rheumatoid factor (IU/mL) & $<20$ & $175(3+)$ & Elevated \\
\hline Anti-citrullinated protein antibody (IU/mL) & $<20$ & 3.5 & Negative \\
\hline Antinuclear antibodies & & $1: 100$ & Negative \\
\hline Double-stranded DNA antibody (IU/mL) & & - & Negative \\
\hline Complement component 3 (mg/dL) & $90-150$ & 127 & Normal \\
\hline Complement component 4 (mg/dL) & $10-40$ & 17 & Normal \\
\hline Cytoplasmic antineutrophil cytoplasmic antibodies (AU/mL) & $<15$ & 113 & Elevated \\
\hline Perinuclear antineutrophil cytoplasmic antibodies (AU/mL) & $<15$ & $<3$ & Normal \\
\hline Lupus anticoagulant & & - & Negative \\
\hline Anticardiolipin antibody $\lg G$ & $<30$ & 65.2 & Elevated \\
\hline Anticardiolipin antibody lgM & $<30$ & 22.6 & Negative \\
\hline Beta-2-glycoprotein I lgG (U/m) & $<40$ & 4.8 & Negative \\
\hline Beta-2-glycoprotein I lgM (U/m) & $<40$ & $<3$ & Negative \\
\hline Hepatitis B surface antigen (mIU) & & - & Negative \\
\hline Hepatitis C virus antibody (mIU) & & - & Negative \\
\hline Human immunodeficiency virus antibody (mIU) & & - & Negative \\
\hline SARS-COV-2 PCR & & - & Negative \\
\hline
\end{tabular}

Laboratory data were repeated two weeks after finishing treatment. Anti-PR3 levels were still elevated (184 $\mathrm{IU} / \mathrm{mL})$. Erythrocyte sedimentation rate $(2 \mathrm{~mm} / \mathrm{h})$ and C-reactive protein $(2 \mathrm{mg} / \mathrm{L})$ levels were within the normal range. Urine analysis demonstrated proteinuria, while 24-h urine showed $210 \mathrm{mg}$ protein/day (creatinine $1170 \mathrm{mg}$, volume $3000 \mathrm{cc}$ ). Complete blood count and liver function test results were unremarkable. The patient was discharged 5 days of admission with improved symptoms during follow-up. We repeated the aCL tests during the patients third month of followup, which again demonstrated positive ACL antibodies $(\mathrm{aCL} \mathrm{Ab}(\mathrm{IgG})=51.5 ; \mathrm{NL}<30)$, confirming our previous diagnosis of APS. During follow-up and examination, gangrene stopped and limited to the area at early points of diagnosis. There was also sufficient blood flow around the mentioned area (Fig. 3).

\section{Discussion}

We present herein a middle-aged male patient with ANCA-associated vasculitis in presence of positive aPL. He had previously received prednisolone and azathioprine due to scleritis, and also prednisolone, methotrexate, and hydroxychloroquine, with suspicion of rheumatic arthritis, which he arbitrarily discontinued. This was followed by index finger gangrene along with paresthesia and mottling sign of the other fingers. The first assumption was vasculitis, in regard to which pulses were present and normal with unremarkable color Doppler sonography, which raised the suspicion of medium and small vessel involvement.

Two primary diagnoses were considered for the patient: 


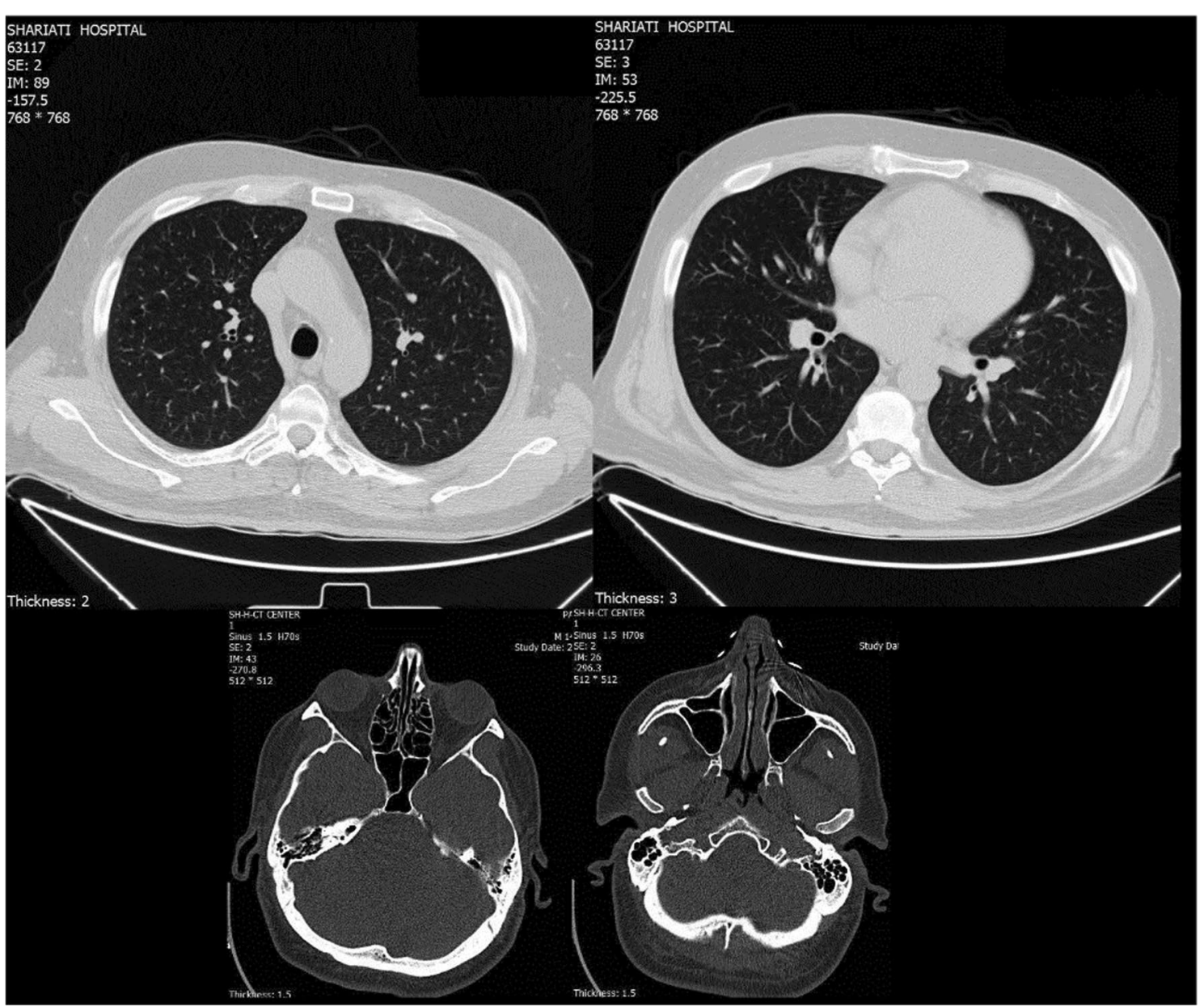

Fig. 2 Normal computed tomography (CT) scan of lung and paranasal sinuses of 48-year-old male suspicious of vasculitis, with no evidence of alveolar hemorrhage, nodules, or cavitation

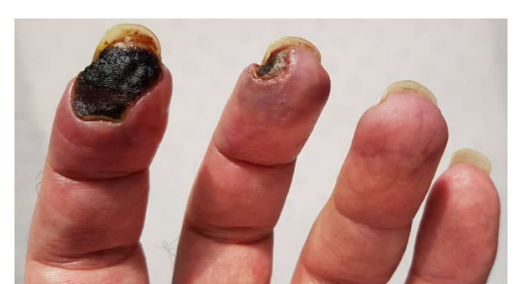

Fig. 3 Limited gangrene of left index and middle finger in a 44-year-old patient with ANCA-associated vasculitis in presence of positive $\mathrm{APL}$, with blood flow around the mentioned areas

1. Vasculitis: based on his history of scleritis, inflammatory arthritis, suspicious of rheumatologic diseases such as rheumatoid arthritis (RA), systemic lupus erythematosus (SLE), and even medium-sized artery vasculitis such as PAN, ANCA-associated vasculitis such as GPA, and also Buerger's disease.

2. Vasculopathy: such as arterial thrombosis, cholesterol emboli, atrial myxoma embolism, and antiphospholipid syndrome (APS).

We treated the patient on the basis of a possible preliminary diagnosis of ANCA-associated vasculitis, although the criterion for a critique of vasculitis was not met since we did not have a tissue biopsy as all of our organ evaluations were normal. Since some clinical settings, such as digital ischemia or scleritis, do not require biopsy if the anti-pR3 test is positive [7], we started a 3-day course of corticosteroid pulse with suspicion of vasculitis, followed by induction of a monthly venous pulse of cyclophosphamide. Based on the positive high levels of anti-PR3 in the patient, other vasculitides were assessed. Color Doppler sonography was performed to rule out large vessel involvements, being unremarkable. Vasculitides involving 
paranasal sinuses and the lung, such as GPA, were ruled out through CT evaluation. EMG-NCV was performed for neurological assessment of peripheral nerves based on vasculitis such as polyarthritis nodosa, also being normal. Cardiac assessment was performed to rule out bacterial endocarditis, atrial myxoma, and thrombosis.

However, while the patient was treated as a case of vasculitis, there was progression in the gangrene, which also started in his middle finger. On further evaluation, aPL was also positive (aCL IgG antibody), with two times the normal value, while SLE tests were negative. With positive levels of aPL, and continuing gangrene process, there was a possibility of thrombosis in the finger arteries. We could not differentiate between vasculitis and vasculopathy, so anticoagulants were also administered based on positive aPL levels and presence of tissue gangrene. Therefore, APS was considered for the patient alongside ANCA-associated vasculitis. Accordingly, the treatment regimen consisted of anticoagulant (warfarin $5 \mathrm{mg} /$ daily) and monthly pulses of cyclophosphamide and a daily dose of $1 \mathrm{mg} / \mathrm{kg}$ prednisolone. The matter of debate is whether aPL tests can be simultaneously positive with vasculitis, especially ANCA-associated vasculitis. This phenomenon has rarely been reported.

APS in presence of vasculitis has been reported in GPA [3], giant cell arteritis [4], EGPA [5], and PAN [6]. The current case, along with other reports, illustrates that these two entities can coexist. Therefore, in evaluating the need for prophylactic anticoagulation for thrombosis prevention, monitoring antiphospholipid antibodies in patients with vasculitis with clinical evidence of internal organ thrombosis may be relevant.

In a study by Sebastian et al., 21 of 176 (12\%) patients with GPA had aCL, including 3 of $29(10 \%)$ patients with thrombosis [8]. Rees et al. also reported a prevalence of $17 \%$ aPL in primary systemic vasculitis [9]. Weider et al. reported 13 patients who presented with venous thromboembolism (VTE) at time of diagnosis of active ANCAassociated vasculitis [1].

Ferenczi et al. [5] reported a case of EGPA in which severe digital gangrene developed in addition to cutaneous vasculitis. Although our patient did not exhibit the hallmarks of EGPA, a similar presentation was observed since, in both studies, the patient developed digital gangrene due to vaso-occlusion in presence of positive aPL. Microthrombosis and vascular occlusion are usually linked with lupus anticoagulant with or without aCL antibodies rather than genuine leukocytoclastic vasculitis. The simultaneous presence of vasculitis and aPL in the current patient may have contributed to development of distal digital gangrene.

In autoimmune disorders, aPL may be aimed at phospholipids or b2-GP-I-associated phospholipids
[10]. Interestingly, b2-GP-I adheres to the surface of endothelial cells, and b2-GP-I reactive antibodies may identify the b2-GP-I endothelial cell-bound complex, resulting in different biological effects, such as upregulation of adhesion molecules and proinflammatory secretion [11]. Hence, although neither sensitive nor specific to systemic vasculitis, these antibodies may play a pathophysiological role in the disease. The antibodies can also lead to vasculitis pathology if present, by affecting the thrombosis mechanism on the compromised endothelium [12].

Also, the absence of involvement of other organs such as kidney or lung does not undermine the diagnosis of ANCA vasculitis since the patient may still develop these features in the future. Although our patient had no history of thrombosis, his first attack may present as digital gangrene. The patient has history of collagen and vascular disease (arthritis, scleritis), and now that he developed gangrene, a positive anti-PR3 test was detected. When the gangrene of the limb is positive with anti-PR3, we do not require a tissue biopsy and the diagnosis of ANCA-associated vasculitis is made. Therefore, we treated both vasculitis (cyclophosphamide) and antiphospholipid (anticoagulant) [7].

\section{Conclusion}

$\mathrm{aCL}$ is present in many disorders included in the differential diagnosis of a patient suspected of having systemic vasculitis. We recommend that they be observed in vasculitis associated with ANCA because they can lead to vascular damage superimposed on life-threatening thrombotic events.

\section{Abbreviations \\ ANCA: Antineutrophil cytoplasmic antibody; aPL: Antiphospholipid antibod- ies; APS: Antiphospholipid syndrome; CT: Computed tomography; COVID-19: Coronavirus disease 2019; C-ANCA: Cytoplasmic antineutrophil cytoplasmic antibodies; EGPA: Eosinophilic granulomatosis with polyarteritis; EMG-NCV: Electromyography and nerve conduction velocity; GPA: Granulomatosis with polyangiitis; IP: Interphalangeal; PAN: Polyarteritis nodosa; RA: Rheumatoid arthritis; SLE: Systemic lupus erythematosus; WG: Wegener's granulomatosis.}

\section{Acknowledgements \\ None.}

Authors' contributions

$M A, E R$, and ML made the disease diagnosis and carried out the patient's treatment course. MR and ER collected the data. RS drafted the manuscript. All authors proofread and accepted the final version of the manuscript.

\section{Funding}

No financial support was received for this case report.

Availability of data and materials

All data regarding this case has been reported in the manuscript. Please contact the corresponding author if you are interested in any further information. 


\section{Declarations}

Ethics approval and consent to participate

Written inform consent was obtained from the patient in our study. The purpose of this research was completely explained to the patient, who was assured that their information will be kept confidential by the researchers. The present study was approved by the Medical Ethics Committee of the academy.

\section{Consent for publications}

Written informed consent was obtained from the patient for publication of this case report and any accompanying images. A copy of the written consent is available for review by the Editor-in-Chief of this journal.

\section{Competing interests}

The authors declare that they have no competing interests.

\section{Author details}

${ }^{1}$ Rheumatology Research Center, Tehran University of Medical Sciences, Tehran, Iran. ${ }^{2}$ Fellowship of Rheumatology, Shariati Hospital, Tehran University of Medical Sciences, Tehran, Iran. ${ }^{3}$ Obstetrician and Gynecologist, Shiraz University of Medical Science, Shiraz, Iran. ${ }^{4}$ Thoracic and Vascular Surgery Research Center, Shiraz University of Medical Sciences, Shiraz, Iran.

Received: 30 August 2021 Accepted: 4 January 2022

Published online: 24 January 2022

\section{References}

1. Weidner S, Hafezi-Rachti S, Rupprecht HD. Thromboembolic events as a complication of antineutrophil cytoplasmic antibody-associated vasculitis. Arthritis Rheum. 2006;55(1):146-9. https://doi.org/10.1002/art.21704.

2. Sammaritano LR. Antiphospholipid syndrome. Best Pract Res Clin Rheumatol. 2020;34(1):101463. https://doi.org/10.1016/j.berh.2019.101463 (Epub 2019 Dec 19)

3. Castellino G, La Corte R, Santilli D, Trotta F. Wegener's granulomatosis associated with antiphospholipid syndrome. Lupus. 2000;9(9):717-20. https://doi.org/10.1191/096120300675018039.

4. Espinoza LR, Jara LJ, Silveira LH, Martínez-Osuna P, Zwolinska JB, Kneer C, Aguilar JL. Anticardiolipin antibodies in polymyalgia rheumatica-giant cell arteritis: association with severe vascular complications. Am J Med. 1991;90(4):474-8 (PMID: 2012088)

5. Ferenczi K, Chang T, Camouse M, Han R, Stern R, Willis J, Cooper KD, Gilliam AC. A case of Churg-Strauss syndrome associated with antiphospholipid antibodies. J Am Acad Dermatol. 2007;56(4):701-4. https://doi.org/ 10.1016/j.jaad.2006.09.028 (Epub 2006 Dec 18).

6. Norden DK, Ostrov BE, Shafritz AB, Von Feldt JM. Vasculitis associated with antiphospholipid syndrome. Semin Arthritis Rheum. 1995;24(4):273-81.

7. Firestein GS. Firestein \& Kelley's textbook of rheumatology, vol. 3. 11th ed. Amsterdam: Elsevier; 2020. p. 1625 (Table 94.3).

8. Sebastian JK, Voetsch B, Stone JH, Romay-Penabad Z, Lo GH, Allen NB, Davis JC Jr, Hoffman GS, McCune WJ, St Clair EW, Specks U, Spiera R, Loscalzo J, Pierangeli S, Merkel PA, Wegener's GranulomatosisEtanercept Trial Research Group. The frequency of anticardiolipin antibodies and genetic mutations associated with hypercoagulability among patients with Wegener's granulomatosis with and without history of a thrombotic event. J Rheumatol. 2007;34(12):2446-50 (Epub 2007 Oct 1).

9. Rees JD, Lança S, Marques PV, Gómez-Puerta JA, Moco R, Oliveri C, Khamashta MA, Hughes GR, D'Cruz DP. Prevalence of the antiphospholipid syndrome in primary systemic vasculitis. Ann Rheum Dis. 2006;65(1):109_ 11. https://doi.org/10.1136/ard.2004.034231.

10. Roubey RA. Autoantibodies to phospholipid-binding plasma proteins: a new view of lupus anticoagulants and other "antiphospholipid" autoantibodies. Blood. 1994;84(9):2854-67 (PMID: 7949161).

11. Meroni PL, Del Papa N, Beltrami B, Tincani A, Balestrieri G, Krilis SA. Modulation of endothelial cell function by antiphospholipid antibodies. Lupus. 1996;5(5):448-50. https://doi.org/10.1177/096120339600500523.
12. Lie JT. Vasculopathy of the antiphospholipid syndromes revisited: thrombosis is the culprit and vasculitis the consort. Lupus. 1996;5(5):368-71. https://doi.org/10.1177/096120339600500506.

\section{Publisher's Note}

Springer Nature remains neutral with regard to jurisdictional claims in published maps and institutional affiliations.
Ready to submit your research? Choose BMC and benefit from:

- fast, convenient online submission

- thorough peer review by experienced researchers in your field

- rapid publication on acceptance

- support for research data, including large and complex data types

- gold Open Access which fosters wider collaboration and increased citations

- maximum visibility for your research: over $100 \mathrm{M}$ website views per year

At $\mathrm{BMC}$, research is always in progress.

Learn more biomedcentral.com/submissions 